\title{
Banana Drift Diffusion in a Tokamak Magnetic Field with Ripples
}

\author{
K. T. Tsang
}

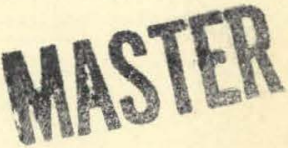

OAK RIDGE NATIONAL LABORATORY 


\section{DISCLAIMER}

This report was prepared as an account of work sponsored by an agency of the United States Government. Neither the United States Government nor any agency Thereof, nor any of their employees, makes any warranty, express or implied, or assumes any legal liability or responsibility for the accuracy, completeness, or usefulness of any information, apparatus, product, or process disclosed, or represents that its use would not infringe privately owned rights. Reference herein to any specific commercial product, process, or service by trade name, trademark, manufacturer, or otherwise does not necessarily constitute or imply its endorsement, recommendation, or favoring by the United States Government or any agency thereof. The views and opinions of authors expressed herein do not necessarily state or reflect those of the United States Government or any agency thereof. 


\section{DISCLAIMER}

Portions of this document may be illegible in electronic image products. Images are produced from the best available original document. 
Printed in the United States of America: Available from National Technical Information Service

U.S. Department of Commerce

5285 Port Royal Road, Springfield, Virginia 22161

Price: Printed Copy \$4.00; Microfiche $\$ 2.25$

This report was prepared as an account of work sponsored by the United States Government. Neither the United States nor the Energy Research and Development Administration/United States Nuclear Regulatory Commission, nor any of their employees, nor any of their contractors, subcontractors, or their employees, makes any warranty, express or implied, or assumes any legal liability or responsibility for the accuracy, completeness or usefulness of any information, apparatus, product or process disclosed, or represents that its use would not infringe privately owned rights. 
Contract No. W-7405-eng-26

FUSION ENERGY DIVISION

BANANA DRIFT DIFFUSION IN A TOKAMAK

MAGNE'IIC FIELD WITH RIPPLES

by

K. T. Tsang

This report was NotiCE the United States not the United States. Neillier Research and Development Administrition, Energy their employess nor any of their, nor any of subcontractors, or their employess contractors.. warranty, express or implied, or assumes any legal Lability or responsibility for the accuracy, completenes or usefulness of any information, apparatus, product or process disclosed, or represents that its use would not infringe privately owned rights.

Date Published: November 1976

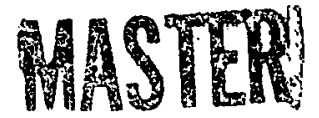

NOTICE This document contoins information of a preliminary nature and was prepared primarily for internal use at the Oak Ridge National Laboratory. It is sublect to revision or correction and therefore does not represent a final report.

OAK RIDGE NATIONAL LABORATORY

Oak Ridge, Tennessee 37830

uperaled by

UNION CARBIDE CORPORATION

for the

ENERGY RESEARCH AND DEVELOPMENT ADMINISTRATION 


\section{THIS PAGE}

\section{WAS INTENTIONALLY \\ LEFT BLANK}


TABLE OF CONTENTS

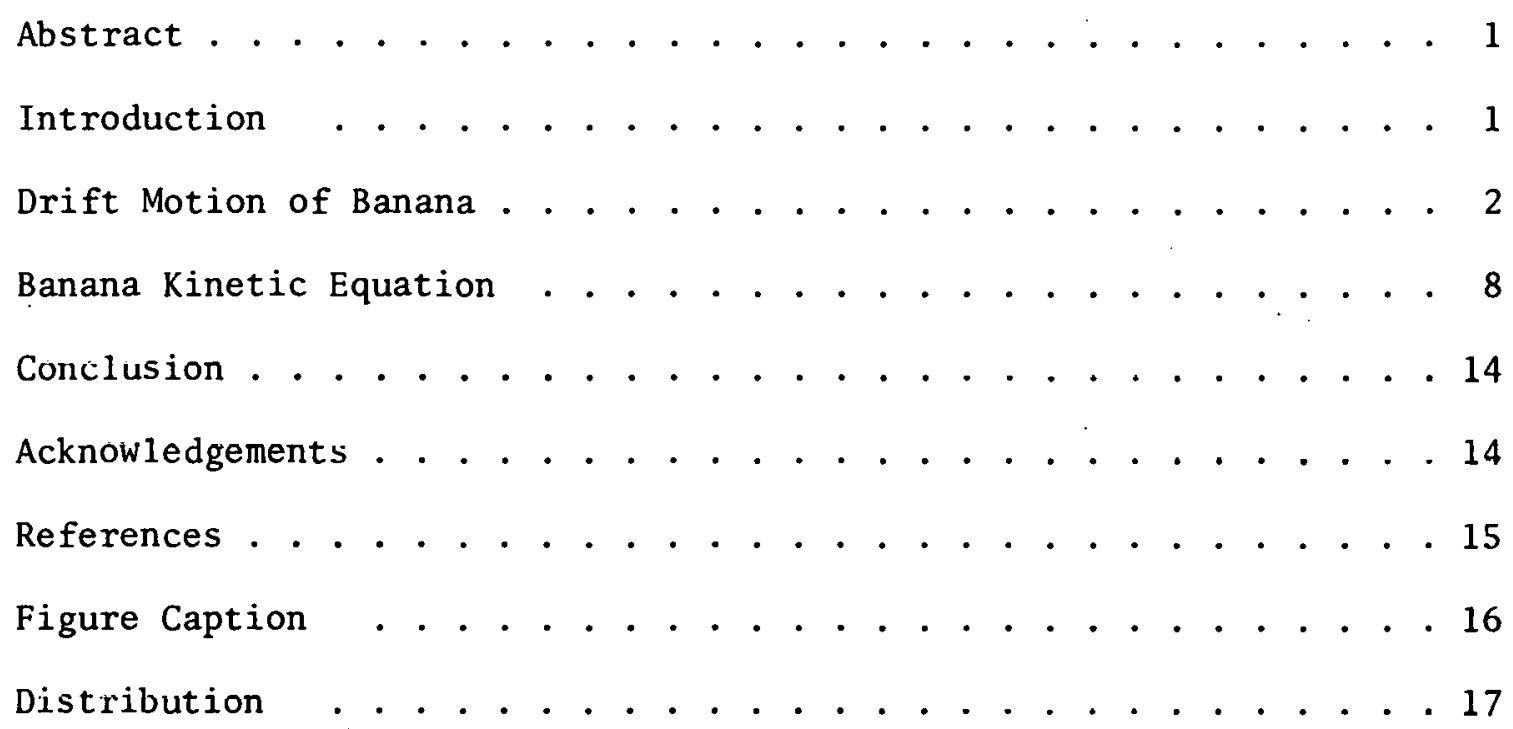




\title{
BANANA DRIFT DIFFUSION IN A TOKAMAK. MAGNETIC FIELD WITH RIPPLES*
}

\author{
K. T. Tsang \\ Oak Ridge National Laboratory, Oak Ridge, Tennessee 37830
}

\begin{abstract}
The drift motions of trapped particles in a tokamak field with ripples lead to a new transport process in large tokamaks in addition to the diffusion process due to particles trapped in the ripples. We study this problem by solving the bounce averaged drift kinetic equation with a model collision operator. It is shown that the "banana drift diffusion" is proportional to the collision frequency when the poloidal banana drift frequency is smaller than the effective collision frequency. This result is contrary to earlier predictions. In a reactor regime, this loss mechanism is shown to be unimportant.
\end{abstract}

\section{INTRODUCTION}

The discrete nature of toroidal magnetic field coils of a tokamak introduces a small, but finite, amplitude modulation on the toroidal magnetic field. These small field modulations in the toroidal direction are usually called "ripples"; their existence destroys the axisymmetry of an ideal tokamak and leads to large particle excursions and hence to particle and energy losses. There are three types of particles in such a magnetic field geometry: those trapped in the ripples which we called "ripple-trapped" particles, those trapped in the toroidal field

*Research sponsored by U.S. Energy Research and Development Administration under contract with Union Carbide Corporation. 
modulation which are called "bananas" because of the shape of their orbits, and those untrapped in both magnetic wells. Much of the previous effort $[1,2]$ in understanding the effects of ripples has been devoted to the particle and energy losses by ripple-trapped particles. In a recent report [3], Davidson raised the possibility of particle and energy losses - which he claimed to be larger than the losses due to rippletrapped particles - through the effect of ripples on the banana particles. This new loss mechanism can be better understood by looking at the effect of ripples on the banana particles. In an axisymmetric tokamak, i.e., without ripples, the banana orbit closes by itself. After bouncing once in the toroidal field, the banana particle goes back precisely to its starting position. With the introduction of ripples, the banana orbit is no longer closed; instead, it drifts in the radial as well as in the poloidal directions. It is this kind of banana drift motion that leads to the new particle and energy transports.

By assuming that the longitudinal adiabatic invariant $\mathrm{J}$ is conserved while the banana is drifting, one can show that the banana drift motion has a finite amplitude proportional to the ripple size. In Section 2, we investigate the single particle drift motion by evaluation of J. Introducing collisions, we can estimate the scaling of the diffusion coefficient. We show that Davidson's calculation [3] corresponds to the limit when the effective collision frequency of the banana particle is larger than the frequency of drift motion of the banana in the ripple field. In Section 3, the drift kinetic equation is averaged over the. banana bounce motion. The resulting equation is then solved by using a model collision operator. Transport coefficients valid for all collisional regimes are calculated. 


\section{DRIFT MOTION OF BANANA}

The longitudinal adiabatic invariant $\mathrm{J}$ for the banana particle is defined by

$$
\mathrm{J}=\oint u_{\mathrm{il}} \cdot \mathrm{d} \ell
$$

where $u_{\|}$is the parallel velocity of the particle, dl is the line element along the magnetic field, and the integration is performed between the turning points. For a particle with speed $U$ and magnetic moment $\mu$, $u_{i l}$ can be written as $U_{\|}=\sqrt{u^{2}-2 \mu B}$, where $B$ is the magnitude of the magnetic field. For a tokamak field resulting from the use of $\mathrm{N}$ toroidal field coils, the B field is chosen to be

$$
\vec{B}=\frac{B_{0}}{1+\epsilon \cos \theta}\left[\frac{\epsilon}{q} \hat{\theta}+[1-\delta(r, \theta) \cos N \phi] \hat{\phi}\right]+\overrightarrow{B_{r}},
$$

where $r, \theta$, and $\phi$ are the usual toroidal coordinates, $\delta(r, \theta)$ is the size of the ripples, $\epsilon=r / R, R$ is the major radius, and $q$ is the safety factor. The dependence of $\delta$ on $r$ and $\theta$ varies with the shape of the toroidal field coils, the shapes of the magnetic flux surfaces we assumed, and the location of the flux surfaces with respect to the coil. For a D-shaped coil with circular flux surfaces centered at the minimum of $\delta$, we can approximate

$$
\delta(r, \theta) \simeq \delta_{0}(r / a)^{n} \exp \left(-\alpha \theta^{2}\right)
$$

where $a$ is the minor radius of the plasma column. The radial component of $B$ is determined by $\nabla \cdot B=0$ which gives 


$$
\mathrm{B}_{\mathrm{r}}=-\mathrm{B}_{0} \delta(\mathrm{r}, \theta) \mathrm{K}(\mathrm{r}, \theta) \in \mathrm{N} \sin (\mathrm{N} \phi),
$$

where $\delta(r, \theta) K(r, \theta) \equiv \int_{0}^{l} \frac{\delta(\chi r, \theta) \chi}{1+\chi \varepsilon \cos \theta} d x$.

Hence to order $\delta$, we have

$$
B \simeq B_{0}(1-\delta \cos N \phi) /(1+e \cos \theta),
$$

and $\mathrm{d} \ell \simeq \mathrm{Rq}(1-\delta \cos \mathrm{N} \phi) \mathrm{d} \theta$

$$
\approx \mathrm{Rq}\left(\mathrm{r}_{0}\right)\left[1-\delta \cos \mathrm{N} \phi+\frac{\Delta \mathrm{r}}{\mathrm{r}_{0}} \mathrm{Q}\left(\mathrm{r}_{0}\right)\right],
$$

where $Q=\partial \mathrm{ln} q / \partial \mathrm{kn} r$,

$\Delta \mathrm{r} \simeq-_{0} \mathrm{q} N f_{0}^{\theta} \delta\left(\mathrm{r}, \theta^{-}\right) \mathrm{K}\left(\mathrm{r}, \theta^{-}\right) \sin \mathrm{N}\left(\mathrm{q}^{-}+\theta_{0}\right) \mathrm{d} \theta^{-}$,

and $\theta_{0}$ is a constant in $\phi=q \theta+\theta_{0}$.

In obtaining $d \ell$, an expansion of $q$ around the unperturbed flux surface at $r=r_{0}$ has been performed.

Combining all these and defining a pitch angle variable

$M=\left[u^{2} / 2-\mu B_{u}(1-0)\right] / 2 \mu B_{0} 0$, we can evaluate $T$ th the lowest order in $1 / \mathrm{Nq}$,

$$
\mathrm{J}=\mathrm{J}_{0}+\mathrm{J}_{1}
$$

where

$$
\begin{aligned}
& \begin{array}{l}
\mathrm{J}_{0}=8\left(\mu \mathrm{B}_{0} \epsilon\right)^{1 / 2} \mathrm{Rq}[\mathrm{E}(\mathrm{M})-(1-\mathrm{M}) \mathrm{K}(\mathrm{M})], \\
\mathrm{J}_{1}=4 \mathrm{Rq}\left(\mu \mathrm{B}_{0} \epsilon\right){ }^{1 / 2}(\cos \mathrm{N} \theta 0) \mathrm{I}, \\
\mathrm{I}=-\mathrm{NqQ} \int_{0}^{\zeta} \mathrm{d} \theta \int_{0}^{\theta} \delta\left(\mathrm{r}, \theta^{-}\right) \mathrm{K}\left(\mathrm{r}, \theta^{-}\right) \sin \mathrm{Nq} \theta^{-} \mathrm{d} \theta^{-}\left(\mathrm{M}-\sin \frac{\theta}{2}\right)^{1 / 2}, \\
S=2 \sin ^{-1} \mathrm{M} \text {, and } \mathrm{K} \text { and } \mathrm{E} \text { are complete elliptic integrals of } \\
\quad \text { first and second kind. }
\end{array} \\
& \text { Note that } \mathrm{M} \text { equals zero for deeply trapped particles, and } \mathrm{M}=1 \text { is } \\
& \text { the boundary between trapped and circulating particles. }
\end{aligned}
$$


At this point, we introduce the coordinates $\alpha$ and $\beta$ which are determined by

$$
\vec{\nabla} \alpha \times \vec{\nabla} \beta=\vec{B}
$$

For the form of magnetic field given by Eq. (1), neglecting small corrections due to $\varepsilon$ and $\delta$, we have

$$
\beta=q \theta-\phi=-\theta_{0},
$$

and

$$
\mathrm{d} \alpha=\mathrm{B}_{0}(\mathrm{r} / \mathrm{q}) \mathrm{dr}
$$

In the $\alpha, \beta$ coordinates, the banana drift velocity is given by [4]:

$$
\begin{gathered}
\bar{\alpha}=\frac{\mathrm{mcu}}{\mathrm{e}}\left(\frac{\partial J}{\partial \beta}\right)\left(\frac{\partial J}{\partial v}\right)^{-1} \\
\overline{\dot{\beta}}=-\frac{\mathrm{mcv}}{\mathrm{e}}\left(\frac{\partial J}{\partial \alpha}\right)\left(\frac{\partial J}{\partial v}\right)^{-1}
\end{gathered}
$$

where the dots over $\alpha$ and $\beta$ represent the time derivatives, the bars the average over the banana orbit, $c$ is the velocity of light, $m$ and $e$ are the mass and charge of the particle, respectively.

$$
\text { From Eq. (3) we have }
$$

$\frac{1}{v} \frac{\partial J_{1}}{\partial u}=2 \operatorname{RqK}(M) /\left(\mu B_{0} \epsilon\right)^{1 / 2}$

$$
\begin{aligned}
& \frac{\partial J}{\partial \beta}=\frac{\partial J_{l}}{\partial \beta}=-4 R q N\left(\mu B_{0} \epsilon\right)^{1 / 2}(\sin N \beta) I \text {, }
\end{aligned}
$$

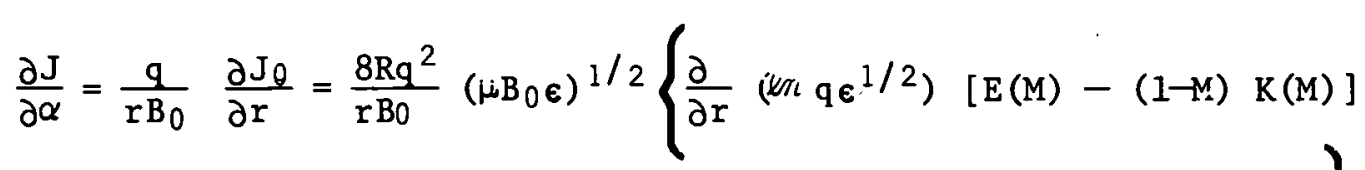

$$
\begin{aligned}
& \left.-\frac{K(M)}{2 r}\left(M-\frac{1}{2}\right)\right\} \text {. }
\end{aligned}
$$


Using the form of $\delta$ given by Eq. (2), I can be evaluated to the lowest order in $1 / \mathrm{Nq}$.

$$
\begin{aligned}
I & \approx \frac{Q}{n+2} \int_{0}^{\zeta} d \theta\left(M-\sin ^{2} \frac{\theta}{2}\right)^{1 / 2} \delta_{0}(r / a)^{n} \\
& =2 Q \delta_{0}(r / a)^{n}[E(M)-(1-M) K(M)] /(n+2) .
\end{aligned}
$$

We can now estimate the order of magnitude of the banana radial drift velocity from Eqs. $(4-6)$ :

$$
\overline{\dot{\mathrm{r}}} \sim \mathrm{NqQ} \delta_{0} \mathrm{U}^{2} / \mathrm{R} \Omega,
$$

where $\Omega=\mathrm{eB}_{0} / \mathrm{mc}$.

This bounce average radial drift velocity $\overline{\dot{r}}$ is a sinusoidal function of $\mathrm{N} \beta$. Hence the radial drift motion due to the ripples is a kind of oscillation whose amplitude is finite and proportional to $\delta$. To estimate the frequency of such oscillation, we need the amplitude of the radial drift,

$$
\tilde{\mathbf{r}}=\int \mathrm{d} l \mathrm{Br} / \mathrm{B} \sim 10_{0}
$$

Therefore, the time needed to complete one oscillation is

$$
\tilde{\boldsymbol{\tau}} \sim \widetilde{\mathrm{r}} / \widetilde{\mathbf{Y}} \sim \mathrm{rRSJ} /\left(\mathrm{NqQU} \mathrm{U}^{2}\right)
$$

The diffusion coefficient due to this banana drift motion can be estimated in two limits. When the effective collision time $\epsilon / \nu$ for the banana is shorter than $\tau$, $1 . e$.

$$
\nu / \epsilon>\mathrm{nqQ} v^{2} / \mathrm{rR} \Omega
$$


where $\nu$ is the collision frequency, the diffusion coefficient is roughly

$$
D \sim(\overline{\dot{r}})^{2} \epsilon^{3 / 2 / \nu}
$$

This is essentially Davidson's result [3]. However, when $\epsilon / \nu$ is longer than $\tau$, i.e.,

$$
\nu / \epsilon<\mathrm{NqQu}^{2} / \mathrm{rR} \Omega
$$

the step size due to banana drift motion is $\tilde{r}$ and hence the diffusion coefficient is

$$
D \sim \widetilde{\mathbf{r}}^{2} \nu(\epsilon)^{-1 / 2}
$$

The condition under which Eq. (7) is valid can be rewritten as

$$
\nu_{*}>\mathrm{Nq}^{2} \mathrm{Qu} / \mathrm{r} \Omega \epsilon^{1 / 2}
$$

where $\nu_{*}=\nu \mathrm{Kqm}^{1 / 2} / \epsilon^{3 / 2} \mathrm{~T}^{1 / 2}$ is the ratio of effective collision frequency to average bounce frequency of the banana particles. For typical reactor parameters such as $\mathrm{N}=20, \mathrm{q}=2.5, \mathrm{Q}=1, \mathrm{~T}_{\mathrm{i}}=10 \mathrm{KeV}, \mathrm{B}=45 \mathrm{~kg}$, $\mathrm{r}=100 \mathrm{~cm}$, and $\epsilon=1 / 3$, we need

$$
\nu_{* i}>0.68,
$$

in order for Davidson's result to be valid. Thus, Eq. (8a) is a very restrictive condition. 


\section{BANANA KINETIC EQUATION}

In this section, analytic calculation of the transport coefficients due to the banana drift motion is presented. Following the development in Ref. [4], we first perform gyro average and then bounce average on the Fokker-Planck equation, and obtain the following equation for the particles trapped in the toroidal field:

$$
\frac{\mathrm{e}}{\mathrm{mc}} \frac{\partial f}{\partial t} \frac{\partial J}{v \partial u}+\frac{\partial f}{\partial \alpha} \frac{\partial J}{\partial \beta}-\frac{\partial f f}{\partial \beta} \frac{\partial J}{\partial \alpha}=\frac{\mathrm{e}}{\mathrm{mc}} \oint \frac{\mathrm{d} \ell}{\mathrm{u}_{\|}} \mathrm{c}(f)
$$

where $C(f)$ is the collision operator. For equilibrium, Eq. (10) becomes

$$
\frac{\partial f}{\partial \alpha} \frac{\partial \mathrm{J}}{\partial \beta}-\frac{\partial f}{\partial \beta} \frac{\partial \mathrm{J}}{\partial \alpha}=\frac{\mathrm{e}}{\mathrm{mc}} \oint \frac{\mathrm{d} \ell}{\mathrm{U}_{\mathrm{H}}} \mathrm{C}(f)
$$

which is'the equation we need for the distribution function of bananas. From Eq. (5) we know $\partial J / \partial \beta$ is of the order of $\delta$, while $\partial J / \partial \alpha$ is of the order of unity. Expanding Eq. (11) in $\delta$, we have

$$
\frac{\partial f_{0}}{\partial \alpha} \frac{\partial J}{\partial \beta}-\frac{\partial f_{1}}{\partial \beta} \frac{\partial J}{\partial \alpha}=\frac{\mathrm{e}}{\mathrm{mc}} \oint \frac{\mathrm{d} \ell}{u_{\|}} \mathrm{C}\left(f_{1}\right),
$$

where $f_{0}=N_{0}\left(\frac{M}{2 \pi T}\right)^{3 / 2} \exp \left(-\frac{m^{2}}{2 T}\right)$ is the lowest order Maxwellian equilibrium in $\delta, N_{0}$ is the density, and $T$ is the temperature.

To solve Eq. (12), we have to assume a form of collision operator. Since it is the ions which are most susceptible to this loss, we need to solve Eq. (12) for ions only. Hence, only ion-1on collisions are included in $C\left(f_{1}\right)$ [5].

$$
C\left(f_{1}\right)=\nu \frac{u_{\|}}{B} \frac{\partial}{\partial \mu} \mu u_{\|} \frac{\partial f_{1}}{\partial \mu}+\nu v_{\|} \text {Pf }
$$


9

where $\nu$ is the collision frequency and $P$ is to be determined selfconsistently by conservation of momentum. The bounce average of $C\left(f_{1}\right)$ leads to

$$
\int \frac{d \ell}{U_{H}} C\left(f_{1}\right)=\frac{\nu}{\epsilon K(M)}\left(\frac{1}{U} \frac{\partial J}{\partial v}\right) \frac{\partial}{\partial M}[E(M)-(1-M) K(M)] \frac{\partial f_{1}}{\partial M},
$$

in which the momentum conserving term does not contribute because its parity is odd in the parallel velocity.

Combining Eqs. (5), (12), and (13), we set

$$
\begin{aligned}
\frac{\partial f_{0}}{\partial \alpha}(\overline{\bar{\alpha}})_{0}\left(\frac{E}{K}-1+M\right) & \sin N \beta-\frac{\partial f_{1}}{\partial \beta}(\overline{\dot{\beta}})_{0}\left[\left(\frac{q^{\prime}}{q}+\frac{1}{2 r}\right)\left(\frac{E}{K}-1+M\right)\right. \\
& \left.-\frac{1}{2 r}\left(M-\frac{1}{2}\right)\right]=\frac{N}{\epsilon}\left[\left(\frac{\epsilon}{K}-1+M\right) \frac{\partial^{2} f_{1}}{\partial M^{2}}+\frac{1}{2} \frac{\partial f_{1}}{\partial M}\right],
\end{aligned}
$$

where $(\overline{\dot{\alpha}})_{0} \simeq 2 \mathrm{NeU^{2 }} \mathrm{Q} \delta_{0}(\mathrm{r} / \mathrm{a})^{\mathrm{n}} \mathrm{mc} / \mathrm{e}(\mathrm{n}+2)$, and $(\overline{\dot{\beta}})_{n} \simeq 2 \epsilon \nu^{2} \mathrm{q} /(\mathrm{r} \Omega)$.

Equation (14) can be solved by separating $f_{1}$ to

$$
f_{1}=f_{+} e^{i N \beta}+f_{-} e^{-i N \beta}
$$

In order that $f_{l}$ be real, $f_{+}$and $f_{-}$are complex conjugates of each other: $f_{+}^{*}=f_{-}$, so we need only an equation governing one of them,

$$
\begin{aligned}
\frac{1}{2 i} \frac{\partial f_{0}}{\partial \alpha}(\overrightarrow{\dot{\alpha}})_{0}\left(\frac{E}{K}-1+M\right) & +\frac{i N}{r} f_{+}(\overline{\dot{\beta}})_{0}\left[\left(Q+\frac{1}{2}\right)\left(\frac{E}{K}-1+M\right)\right. \\
& \left.-\frac{1}{2}\left(M-\frac{1}{2}\right)\right]+\frac{v}{\epsilon}\left[\left(\frac{E}{K}-1+M\right) \frac{\partial^{2} f_{+}}{\partial M^{2}}+\frac{1}{2} \frac{\partial f_{+}}{\partial M}\right]=0
\end{aligned}
$$


Equation (15) is a second order differential equation of $f_{+}$with complicated coefficients. We cannot proceed unless we can replace $M-1+E / K$ by a tractable expression. This is possible by expanding $E$ and $K$ in small argument $M$,

$$
\frac{\mathrm{E}}{\mathrm{K}}-1+\mathrm{M} \approx \mathrm{M} / 2
$$

Except near $M=1$, which is the boundary between circulating and trapped particles, $M / 2$ is a fairly good approximation of $M-1+E / K$. Equation (15) is then further simplified to

$\frac{\nu}{2 \epsilon}\left(M \frac{\partial^{2} f_{+}}{\partial M^{2}}+\frac{\partial f_{+}}{\partial M}\right)+\frac{i N}{r} f_{+}(\overline{\dot{\beta}})_{0}\left[\left(Q-\frac{1}{2}\right) \frac{M}{2}+\frac{1}{4}\right]=\frac{i M}{4} \frac{\partial f_{0}}{\partial \alpha}(\overline{\dot{\alpha}})_{0}$.

We have to make one more assumption before we can solve Eq. (16) analytically. In the outer half of the plasma column where the effect of ripples is most significant, $Q$ is usually larger than $1 / 2$. Ignoring $1 / 4$ compared with $\left(Q-\frac{1}{2}\right) M / 2$ will not introduce an artifical sign change of the coefficient of $f_{+^{*}}$. Such an approximation would change the answer only by a factor of unity, since only when $\partial J / \partial \alpha=0$ can a new physical entity appear, namely the superbanana [6].

Using the boundary condition that $f_{+}=0$ at the trapped circulating boundary, i.e., $M=1$, and $\partial f_{+} / \partial M$ is well behaved at $M=0$, we can solve Eq. (16) approximately by expanding $f_{+}$into a series of Bessel functions

$$
f_{+}=\sum_{n} A_{n} j_{0}\left(\alpha_{n} M\right)
$$

where $j_{0}$ is the zeroth order Bessel function and $\alpha_{n}$ is the $n$th zero of $j_{0}(x)$. The coefficients $A_{n}$ can be obtained by substituting Eq. (17a) in Eq. (16) and using the orthogonality condition: 


$$
\int_{0}^{1} t j_{0}\left(\alpha_{m} t\right) j_{0}\left(\alpha_{n} t\right) d t=\delta_{m n}\left[j_{i}\left(\alpha_{n}\right)\right]^{2} / 2 .
$$

Thus we get

$$
A_{n}=\frac{i}{2} \frac{\partial f_{0}}{\partial \alpha} \frac{\overline{(\dot{\alpha})_{0}}}{\alpha_{n} j_{l}\left(\alpha_{n}\right)}\left[-\frac{\nu}{2 \varepsilon} \alpha_{n}^{2}+\frac{i N}{2 r}(\overline{\dot{\beta}})_{0} \quad\left(Q-\frac{1}{2}\right)\right]^{-1}
$$

Going back to Eq. (10), it is easy to show that the flux surface averaged particle and heat fluxes in $\alpha$ direction are

$$
\Gamma_{\alpha}=\int \frac{d \theta}{2 \pi} \int d \vec{V} \oint \frac{d \beta}{2 \pi} f \bar{\alpha}
$$

and

$$
\widetilde{Q}_{\alpha}=\int \frac{d e}{2 \pi} \int d \vec{V} \dot{\phi} \frac{d \beta}{2 \pi} f \bar{\alpha} \frac{\bar{m}}{2} \nu^{2}
$$

Since $\overline{\dot{\alpha}}$ is proportional to sin $N \beta$, we have

$$
\Gamma_{\alpha}=\int \frac{\mathrm{d} \theta}{2 \pi} \int \mathrm{d} \overrightarrow{\mathrm{V}}\left(\operatorname{Im} f_{+}\right)(\overline{\dot{\alpha}})_{0}\left(\frac{E}{\mathrm{~K}}-1+\mathrm{M}\right)
$$

and

$$
\widetilde{\mathrm{Q}}_{\alpha}=\int \frac{\mathrm{d} \theta}{2 \pi} \int \mathrm{d} \overrightarrow{\mathrm{V}}\left(\operatorname{Im} f_{+}\right) \overline{(\dot{\alpha})_{0}}\left(\frac{\mathrm{E}}{\mathrm{K}}-1+\mathrm{M}\right) \frac{\mathrm{m}}{2} v^{2}
$$

where $\int \mathrm{dV}$ is the integral over the trapped particles only and after averaging over $\theta$, it is approximately $\int^{1} \frac{d \theta}{2 \pi} \int d V \simeq 2 \sqrt{2 \varepsilon} \pi \int_{0}^{\omega} u^{2} d u \int_{0}^{1} d M$. Combining Eqs. (17) and (18), we have

$$
\begin{aligned}
& \Gamma_{\alpha}=\sum_{m=1}^{\infty} \frac{\pi(2 \epsilon)^{1 / 2}}{4} \int_{0}^{\infty} v^{2} \mathrm{~d} v \frac{(\nu / \epsilon)\left[(\overline{\dot{\alpha}})_{0}\right]^{2}\left(\partial f_{0} / \partial \alpha\right)}{(\nu / 2 \epsilon)^{2} \alpha_{\mathrm{n}}^{4}+(\mathrm{N} / 2 \mathrm{r})^{2}(\dot{\bar{\beta}})^{2}(Q-1 / 2)^{2}},
\end{aligned}
$$

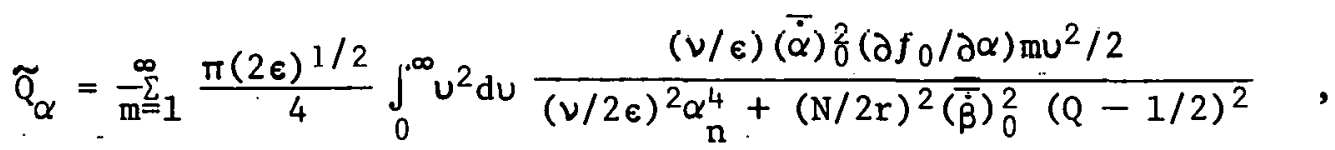


which are essentially Davidson's result if we neglect the $(\overline{\bar{\beta}})_{0}$ terms in the denominators. More explicitly worked out forms for $\Gamma$ and $\widetilde{Q}$ are:

$\mathrm{F} \alpha=-\left(\frac{2}{\pi \epsilon}\right)^{1 / 2} \nu_{i i}\left[\frac{Q \delta_{0}(\mathrm{r} / \mathrm{a} .)^{\mathrm{n}}}{(\mathrm{m}+2)(Q-1 / 2)} \frac{\mathrm{r}^{2} \mathrm{~B}}{\mathrm{q}}\right]^{2}\left[\frac{\mathrm{N}_{0}^{\prime}}{\mathrm{N}_{0}}+\frac{\mathrm{e} \phi^{\prime}}{\mathrm{T}} \lambda_{1}+\left(\lambda_{2}-\frac{3}{2} \lambda_{1}\right) \frac{\mathrm{T}^{\prime}}{\mathrm{T}}\right] \mathrm{N}_{0}$,

and

$\widetilde{Q}_{\alpha}=-\left(\frac{2}{\pi \epsilon}\right)^{1 / 2} \nu_{i i} \mathrm{~T}\left[\frac{\mathrm{Q} \delta_{0}\left(\frac{\dot{\mathrm{r}}}{\mathrm{a}}\right)^{\mathrm{n}}}{(\mathrm{n}+2)\left(\mathrm{Q}-\frac{1}{2}\right)} \frac{\mathrm{r}^{2} \mathrm{~B}}{\mathrm{q}}\right]^{2}\left[\left(\frac{\mathrm{N}_{0}^{-}}{\mathrm{N}_{0}}+\frac{\mathrm{e} \phi^{-}}{\mathrm{T}}\right) \lambda_{2}+\left(\lambda_{3}-\frac{3}{2} \lambda_{2}\right) \frac{\mathrm{T}^{-}}{\mathrm{T}}\right] \mathrm{N}_{0}$

where

$$
\begin{aligned}
\lambda_{n} & =\sum_{j=1}^{\infty} \int_{0}^{\infty} \frac{d x x^{4} \xi(x) e^{-x^{2}} x^{2 n}}{x^{4}+\nu^{2} \alpha_{j}^{4}[\xi(x)]^{2}}, \\
\xi(x) & =\frac{1}{x^{3 / 2}}\left[\left(1-\frac{1}{2 x^{2}}\right) \operatorname{Er} f(x)+e^{-x^{2} / \pi^{1 / 2}} x\right], \\
\bar{\nu} & =\left(\nu_{i i^{2}} / 2 \epsilon\right) /\left[\frac{N}{2 r}\left(Q-\frac{1}{2}\right) \in q \mathrm{~T} / \mathrm{mr} \Omega\right], \\
\nu_{i i} & =2^{1 / 2} \pi_{0} \mathrm{~N}^{4} \ln \Lambda / \mathrm{m}^{1 / 2} \mathrm{~T}^{3 / 2}, \text { and } x=u(\mathrm{~m} / 2 \mathrm{~T})^{1 / 2} .
\end{aligned}
$$

Since it is the ion species that diffuses most rapidly by this process, the neutrality condition requires

$$
\left(\frac{N_{0}^{\prime}}{N_{0}}+\frac{e \phi^{\prime}}{T}\right) \lambda_{1}+\left(\lambda_{2}-\frac{3}{2} \lambda_{1}\right) \frac{T^{\prime \prime}}{T}=0
$$

Hence the resulting energy flux is

$$
\tilde{Q}_{\alpha}=-\left(\frac{2}{\pi}\right)^{1 / 2} \frac{\left[\mathrm{Q} \delta_{0}\left(\frac{r}{a}\right)^{n} \mathrm{rB}\right]^{2}}{\left(\mathrm{Q}-\frac{1}{2}\right)(\mathrm{n}+2)^{2} \mathrm{q}} \cdot \frac{\mathrm{N} \epsilon^{3 / 2} \mathrm{~T}}{\mathrm{~m} \Omega} \cdot \bar{v}\left(\lambda_{3}-\frac{\lambda_{2}^{2}}{\lambda_{1}}\right) \mathrm{N}_{0} \mathrm{~T}^{-},
$$


where all the collision frequency dependences are embodied in $x=\bar{v}$ $\left(\lambda_{3}-\lambda_{2}^{2} / \lambda_{1}\right)$. Numerical integration has been performed to evaluate $x$ as a function of $\bar{v}$. From the definition, $\bar{v}$ is essentially the ratio between the effective collision frequency and $\mathrm{N}$ times the toroidal drift velocity of the banana. The dependence of $x$ on $\bar{\nu}$ is plotted in Fig. 1. For $\bar{v}$ large, $x$ is proportion to $\bar{v}^{-1}$, which is the result obtained by Davidson [3]. However, as $\bar{v}$ decreases, the $1 / \bar{v}$ dependence changes gradually to a $\bar{\nu}$ dependence. This result agrees with our phenomenological derivation in Section 2. In Fig. 1, the actual dependence of $x$ on $\bar{v}$. is represented by the solid curve. Davidson's result [3] is represented by the dash straight line. They agree with each other very well in the large $\bar{\nu}$ limit. However, at around $\bar{\nu} \approx 3$, the solid curve turns away from the dash line and approaches to a linear behavior with $\bar{\nu}$ as $\bar{\nu}$ decreases. For the same parameters just preceeding Eq. (9), this is equivalent to saying that Davidson's analysis no longer holds when $\nu_{\Re i} \leqslant 0.5$, which is quite close to our estimation in Eq. (9).

If we take into account the fact that trapped particles exist only when $v$ is larger than $v_{*} \equiv v_{*}^{1 / 4}(2 \mathrm{~T} / \mathrm{m})^{1 / 2}[7]$, the lower limit of integration in the definition of $\lambda_{n}$ should be replaced by $\nu_{*}^{1 / 4}$. For the parameters just preceeding Eq. (9), $\bar{\nu}$ is related to $\nu_{* i}$ by $\bar{\nu}=5.88 \nu_{* i}$. The effect of this is shown by the dash-dot curve in Fig. 1 . For $\bar{v}<10$, the solid curve and the dash-dot curve are practically the same. For larger $\bar{\nu}$, the dash-dot curve rapidly dips below the solid curve. This implies that by the time when Davidson's result is valid, there are not many trapped particles left. 


\section{CONCLUSION}

The transport processes induced by the drift motion of bananas in a tokamak field with ripples have been derived by solving the banana drift kinetic equation with a bounce averaged pitch angle collision operator. The result agrees with what one would obtain by a simple physical argument. Previous calculation [3] of this effect is shown to be valid only in high collision frequency limits and suggests that it cannot be extrapolated to low collision frequency. For typical reactor parameters, this loss mechanism is probably not very significant compared to the ripple trapping loss mechanism.

\section{ACKNOWLEDGMENTS}

I wish to thank S. Fisher, T. Uckan, and J. Whitson for their help in numerical integration. I also appreciate useful discussions with J. D. Callen, J. N. Davidson, and N. A. Uckan. 


\section{REFERENCES}

[1] STRINGER, T. E., Nuc1. Fusion 12 (1972) 689.

[2] CONNER, J. W., HASTIE, R. J ., Nuc1. Fusion 13 (1973) 221.

[3] DAVIDSON, J. N., Argonne National Laboratory/CTR Technical Memorandum No. 62, March 1976, submitted to Nucl. Fusion for publication.

[4] HASTIE, R. J., TAYLOR, J. B., HAAS, F. A., Annals of Physics 41 (1967) 302 .

[5] ROSENBluth, M. N., HAzeltine, R. D. HINTON, F. L., Phys . of Fluids 15 (1972) 116.

[6] KADOMTSEV, B. B., POGUTSE, O. P., Nucl. Fusion 11 (1971) 67.

[7] TSANG, K. T., CALlEN, J. D., Phys. of Fluids 19 (1976) 667. 


\section{FIGURE CAPTION}

Fig. 1. Comparison of present (solid line) and Davidson's (dashed line) results for the normalized ion heat conductivity due to banana drift motion as function of collisionality. The dash-dot line is the Ion heat conductivity after adjustment for the fraction of trapped particles that can exist for the parameters: $N=20, q=2.5, Q=1$, $\mathrm{TI}=10 \mathrm{KeV}, \mathrm{B}=45 \mathrm{~kg}, \mathrm{r}=100 \mathrm{~cm}$, and $\epsilon=1 / 3$. 


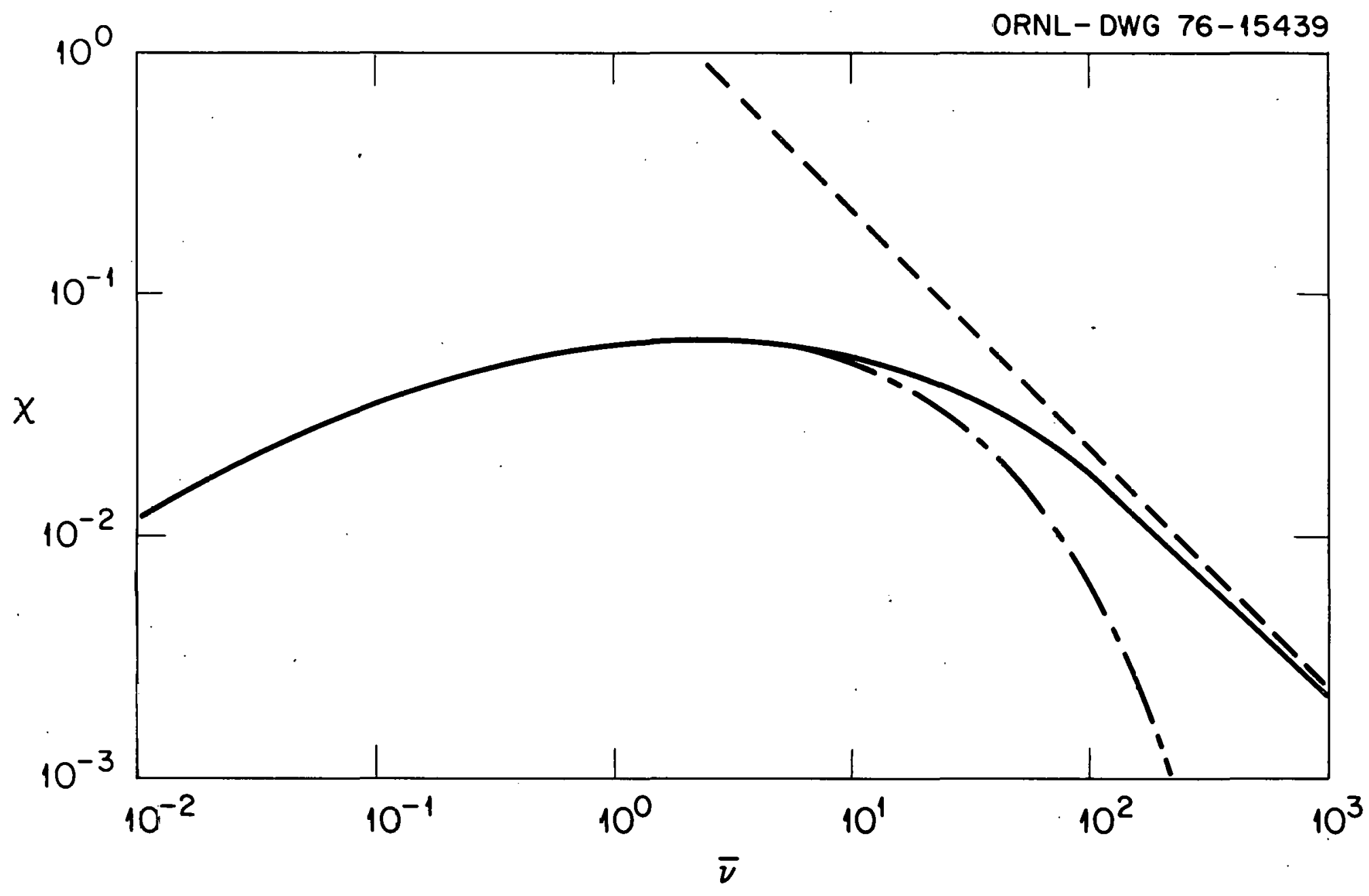

Figure 1 
THIS PAGE

WAS INTENTIONALLY

LEFT BLANK 


\section{INTERNAL DISTRIBUTION}

ORNL/TM- 5630

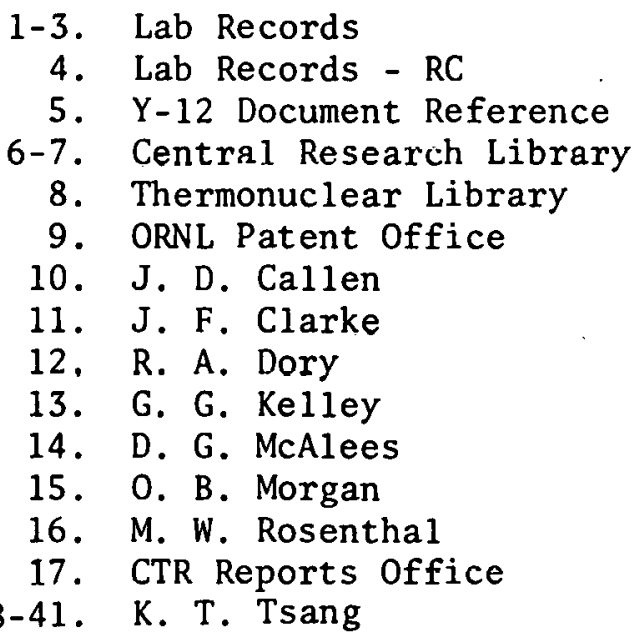

EXTERNAL DISTRIBUTION

42. Plasma Physics Library, Plasma Physics Laboratory, Prid eton Univ., Forrestal Campus, P.0. Box 451, Princeton, NJ 08540

43. Controlled Thermonuclear Research Library, Lawrence Livermore Laboratory, P.0. Box 808, Livermore, CA 94550

44. Q Division Library, c/o F. L. Ribe, Los Alamos Scientific Laboratory, P.0. Box 1663, Los Alamos, NM 87544

45. Controlled Thermonuclear Research Library, c/o Weston M. Stacey, Jr., Argonne National Laboratory, 9700 S. Cass Ave., Argonne, IL 60439

46. CTR Computer Center, c/o Dr. John Killeen, Lawrence Livermore Laboratory, P.0. Box 808, Livermore, CA 94550

47. Librarian, Culham Laboratory, U.K. Atomic Energy Authority, Abingdon, Oxon, OX14, 3DB, United Kingdom

48. Ruth Lengye, Bibliothek, Max Planck Institut für Plasmaphysik, 8046 Garching bei München, Federal Republic of Germany

49. Library, Centre de Recherches en Physique des Plasmas, 21 Avenue des Bains, 1007, Lausanne, Switzerland

50. A. M. Dupas, Documentation S.I.G.N., Départment de la Physique du Plasma et de la Fusion Controlée, Association EURATOM-CEA sur la Fusion, Centre d'Etudes Nucléaires, BP 85 Centre Du TRI 38041 Grenoble Cedex (France)

51. Bibliothèque, Service du Confinement des Pla.smas, C.E.A., B.P. No. $\dot{b}, \dot{2}$, fontenay-aux-Roses (Seille) France 
52. Librâิy, International Centre for Theoretical Physics, Trieste, Italy

53. Library, Laboratorio Gas Ionizzati, Frascati, Italy

54. V. E. Ivanov, Physical-Technical Institute of the Ukranian Academy of Sciences, Sukhumi, U.S.S.R.

55. L. M. Kovrizhnikh, Lebedev Institute of Physics, Academy of Sciences of the U.S.S.R., Leninsky Prospect 53, Moscow, U.S.S.R.

56. Thermonuclear Laboratory, Kurchatov Institute of Atomic Energy, 46 Ulitsa Kurchatova, P.0. Box 3402, Moscow, U.S.S.R.

57. Library, Institute for Plasma Physics, Nagoya University, Nagoya, Japan 464

58. Library, FOM-Institut voor Plasma-Fysica, Rijnhuizen, Jutphaas, Netherlands

59. Plasma Physics Group, Department of Engineering Physics, Australian National University, P.0. Box 4, Canberra A.C.T. 2600 Australia

60. Thermonuclear Library, Japan Atomic Energy Research Institute, Tokai, Naka, Ibaraki, Japan

61. CTR Reading Room, c/o Prof. Dieter J. Sigmar, Room 37-391, MIT, Cambridge, MA 02139

62. CTR Reading Ronm, c./o Prof. D. W. Kerst, Dept. of Physics, Sterling Ha11, Univ. of Wisconsin, Madison, WI 53706

63. CTR Reading Room, c/o Prof. I. B. Bernstein, Yale Univ., New Haven, CT 06510

64. Center for Plasma Physics and Thermonuclear Research, c/o D. W. Ross, Univ. of Texas, Physics Dept., Austin, TX 78712

65. CTR Reading Room, c/o Prof. B. D. Fried, Physics Dept., Univ. of California, Los Angeles, CA 90024

66. CTR Reading Room, c/o Prof. David C. Montgomery, Physics \& Astronomy Dept., Univ. of Iowa, Iowa City, IA 52240

67. Magneto-F1uid-Dynamics Library, Courant Inst. of Math. Sci., New York Univ., 251 Mercer St., New York, NY 10012

68. CTR Reading Room, c/o Prof. Allan N. Kaufman, Physics Dept., Univ. of California, Berkeley, CA 94720

69. CTR Reading Room, c/o Prof. W. B. Thompson, Physics Dept:, Univ. of California, San Diego, La Jolla, CA 92037 
70. CTR Reading Room, c/o Prof. Alvin W. Trivelpiece, Dept. of Physics \& Astronomy, Univ. of Maryland, College Park, MD 20742

71. CTR Reading Room, c/o Prof. T. Kammash, 103 Research Admin. Bldg., N. Campus, Univ. of Michigan, Ann Arbor, MI 48105

72. CTR Reading Room, c/o Dr. Ravi N. Sudan, Phillips Hall, Corne 11 Univ., Ithaca, NY 14850

73. Prof. Marsha11 N. Rosenbluth, Institute for Advanced Study, Princeton, NJ 08540

74. CTR Reading Room, c/o Prof. R. Gross, Plasma Research Lab., Columbia Univ., New York, NY 10027

75. CTR Reading Room, c/o Prof. Roy Gould, California Inst. of Tech., M.S. 116-81, Pasadena, CA 91125

76. Dr. Nicholas A. Krall, Science Applications, Inc., P.0. Box 2354, 1200 Prospect St., La Jolla, CA 92037

77. CTR Reading Room, c/o Dr. Jay P. Boris, Plasma Physics, Naval Research Laboratory, Washington, DC 20390

78. Professor A. Simon, Dept. of Mechanical \& Aerospace Sciences, University of Rochester, Rochester, NY 14627

79. CTR Library, c/o Dr. Alan F. Haught, United Technologies Research Labs, East Hartford, CT 06108

80. Dr. Robert E. Price, Division of Magnetic Fusion Energy, G-234, Energy Research and Development Administration, Washington, DC 20545

81. Dr. Bennett Miller, Division of Magnetic Fusion Energy, G-234, Energy Research and. Development Administration, Washington, DC 20545

82. Dr. Arthur Sleeper, Division of Magnetic Fusion Energy, G-234, Energy Research and Development Administration, Washington, DC 20545

83. Dr. Walter Sadowski, Division of Magnetic Fusion Energy, G-234, Energy Research and Development Administration, Washington, DC 20545

84. Dr. D. H. Priester, Division of Magnetic Fusion Energy, G-234, Energy Research and Development Administration, Washington, DC 20545

85. Mr. E. E. Kintner, Division of Magnetic Fusion Energy, G-234, Fnergy Research and Meveinpment Administration, Washington, nr. 20545 
86. Dr. L. D. Pearlstein, L-388, Lawrence Livermore Laboratory, P.0. Box 808, Livermore, CA 94550

87. Dr. J. P. Friedberg, Los Alamos Scientific Laboratory, Los Alamos NM 87544

88. Dr. David J. Rose, Dept. of Nuclear Engineering, MIT, Cambridge, MA 02139

89. Dr. Gareth E. Guest, General Atomic Co., P.0. Box 81608, San Diego, CA 92138

90. Dr. Claude Mercier, Service du Theorie des Plasmas, Centre d'Etudes Nucléaires, Fontenay-aux-Roses (Seine) France

91. Dr. J. B. Taylor, Culham Laboratory, UKAEA Abingdon, Oxon, OX14 3DB, United Kingdom

92. Dr. D. Pfirsch, Institute for Plasma Physics, 8046 Garching bei München, Federal Republic of Germany

93. Dr. V. D. Shafranov, I. V. Kurchatov Inst. of Atomic Energy, 46 Ulitsa Kurchatova, P:0. Box 3402, Moscow, U.S.S.R.

94. Dr. Harold Grad, Courant Inst. of Math. Sci., New York Univ., 251 Mercer St., New York, NY 10012

95. Dr. J. G. Cordey, Culham Laboratory, UKAEA, Abingdon, Oxon, OX14, 3DB, United Kingdom

96. Dr. David Baldwin, L-388, Lawrence Livermore Lab., P.0. Box 808 , Livermore, CA 94550

97. Prof. Bruno Coppi, Dept. of Physics, MIT, Cambridge, MA 02139

98. Dr. Harold P. Furth, Princeton Plasma Physics Lab., Princeton Univ., P.0. Box 451, Princeton, NJ 08540

99. Dr. Paul H. Rutherford, Princeton Plasma Physics Lab., Princeton Univ., Princeton, NJ 08540

100. Dr. Herbert H. Woodson, Dept. of Electrical Engineering, Univ. of Texas, Austin, TX 78712

101. Research \& Technical Support Div., Oak Ridge Operations, Energy Research and Development Administration, P. O. Box E, Oak Ridge, TN 37830

102-128. Technical Information Center, Energy Research and Development Administration, P. O. Box 62, Oak Ridge, TN 37830 